\title{
Framework for Measuring the Resilience of Utility Poles of an Electric Power Distribution Network
}

\author{
Md. Morshedul Alam ${ }^{1} \cdot$ Berna Eren Tokgoz ${ }^{1} \cdot$ Seokyon Hwang ${ }^{2}$
}

Published online: 24 May 2019

(C) The Author(s) 2019

\begin{abstract}
The utility poles of an electric power distribution system are frequently damaged by wind-related disasters. This study notes that the wooden poles are particularly vulnerable to such disasters and the failures of the poles can cause a network-level failure leading to short- or longterm power outages. To mitigate the problem, this study proposes a framework for measuring the resilience of the wooden utility poles based on the angular deflection of a pole due to the wind force. Given the existing inclination angle of a pole, the angular deflection is measured by finite element analysis using ANSYS $^{\circledR}$ Workbench $^{1}$ to determine the resilience area under various wind speeds. For this, the conditions of load and support for a pole, which are called boundary conditions in ANSYS ${ }^{\circledR}$, are generated. The proposed framework also includes an approach to cost-benefit analysis that compares different strategies for corrective action. The results of the case study in which the framework was applied show that the proposed framework can be effectively utilized by electric power distribution companies to increase the resilience of their systems.
\end{abstract}

Keywords Angular deflection · Cost-benefit analysis · Finite element analysis · Pole damage - Utility system resilience $\cdot$ Wind-related disaster

Berna Eren Tokgoz

btokgoz@lamar.edu

1 Department of Industrial Engineering, Lamar University, Beaumont, TX 77710, USA

2 Construction Management Program, Lamar University, Beaumont, TX 77710, USA

\section{Introduction}

The power distribution system is one of the most vital components of modern society. But this system is vulnerable to disasters caused by wind-related events such as tornados and hurricanes, which frequently incurs power outages. Extreme weather events and climate change are the two most significant causes of power outages in various parts of the world (Mukherjee et al. 2018). As the intensity of the two causes has increased, power outages due to these causes have also significantly increased (Kenward and Raja 2014). Among the various components of the power distribution system, the poles are frequently damaged by wind-related disasters, which ultimately leads to hours of power outages that extend for days or even weeks, depending on the intensity of a particular disaster. For example, Hurricane Harvey seriously damaged approximately 5000 power distribution poles in Texas in 2017 (AEP Texas 2017). As the severity and frequency of natural hazard-induced disasters are increasing year by year (NOAA 2017), it is imperative for power utility companies to develop resilient utility poles for the electric power distribution network.

There are various factors causing damages to a pole, including the trees and branches located nearby power lines and poles, structural deterioration of a pole, flooding, storm surges, debris produced by winds, and so on (Pellicane and Franco 1994; Oudjene and Khelifa 2009; Schmidt and Kaliske 2009; Ryan et al. 2014). The present study notes that inclined poles become more susceptible to these factors during a wind-related disaster. Therefore, the goal of this study is to develop a practical methodology that can help to increase the resilience of power distribution poles threatened by wind-related disasters. The research objectives of this study are: (1) to create a photogrammetry- 
based method for evaluating the condition of a pole based on its angle of inclination; (2) to determine the resilience areas based on the condition of a pole; (3) to develop a damage prediction method using finite element analysis; and (4) to conduct a cost-benefit analysis of resilience improvement strategies. The results of our research indicate that the proposed methodology is useful in assessing the health condition of each pole and in evaluating strategies for preventive maintenance of poles.

This article is organized as follows. Section 2 presents a summary of the literature relevant to the resilience of power distribution systems, pole failures, and cost-benefit analysis. Section 3 briefly delineates the material and geometrical properties of wooden poles. Section 4 discusses the proposed methodology for measuring the resilience of poles and develops a cost-benefit analysis method applied in the present study. A case study in which the proposed methodology was applied and evaluated is presented in Sect. 5, while Sect. 6 concludes the present study.

\section{Literature Review}

This section summarizes the literature review in terms of three subject areas: resilience of power distribution systems, failures of the poles of electrical distribution system, and cost-benefit analysis.

\subsection{Resilience of Power Distribution Systems}

As the severity and frequency of natural hazard-induced disasters increase year by year (NOAA 2017), utility companies are very keen to develop resilient power distribution systems. An electric pole-based resilience assessment can establish a strong base for prestorm planning. The literature shows a variety of definitions of resilience, and there is no consensus on the one accepted definition of the term. Resilience can be simply defined as the capability of a system to anticipate and absorb threats to mitigate adverse effects as well as develop response and recovery actions to resume its normal operations (Eren Tokgoz and Gheorghe 2013). According to Hosseini et al. (2016, p. 4), resilience is "the ability of an entity or system to return to normal condition after the occurrence of an event that disrupts its state." Similarly, Nan and Sansavini $(2017$, p. 36) define resilience capability as "the ability of the system to withstand a change or a disruptive event by reducing the initial negative impacts, by adapting itself to them and by recovering from them." Haimes (2009, p. 498) also defines resilience as "the ability of the system to withstand a major disruption within acceptable degradation parameters and to recover with a suitable time and reasonable costs and risks."

The concept of resilience is multidimensional, and the quantification of it depends on several factors (MacKenzie and Zobel 2016). It is hard to consider all possible factors and vulnerabilities against various disasters, but preparation, response, recovery, and mitigation efforts, which are resilience strategies, can reduce the adverse consequences of disasters (Eren Tokgoz et al. 2017). Carlson et al. (2012) claimed that the concept of resilience plays a vital role in assessing the threats for various entities, such as owners and operators of critical infrastructures, communities, regions, and the nation. Resilience can be assessed at the asset/facility level and critical infrastructure level to develop methodologies that provide resilience-related information to critical infrastructure owners, operators, state, and local partners. Power distribution systems are complex systems and increasing their resilience by implementation of some mitigation actions could be costly. Moreover, investment in increased resilience of power distribution systems involves several complexities, such as a lower rate of future return, strict regulatory restrictions by the Public Utility Commission (PUC), lack of strong value propositions, and inadequate incentives (Mukhopadhyay and Hastak 2016). Mukhopadhyay and Hastak stated that the present investment analysis framework has flaws; hence it is not cogent and persuasive to PUC. A report published by the U.S. Executive Office of the President mentioned that investment in electric grid modernizations and increased resilience of the electric grids would reduce hardship and recovery time during weather-related disasters as well as cut down the costs associated with damages based on these disasters over time (Executive Office of the President 2013). According to this report, the annual cost of lost power due to outage consists of foregone output and wages, spoiled inventory, delayed production, inconvenience, and damage to the electric grid itself.

\subsection{Failures of the Poles of Electrical Distribution System}

Several studies have been conducted on the failure of utility poles in the power distribution system. Shafieezadeh et al. (2013) found that wooden poles often fail due to a wind load greater than the flexural capacity of a pole. Han (2008) examined two mechanisms that cause the failure of poles - flexural failure due to the wind load and foundation failure. A structural analysis involving wind loads and the probabilities of failure has been conducted in the Caribbean Disaster Mitigation Project (1996). In this project, the wooden pole was assumed to be a cantilever beam that will fail if the bending stress exceeds the modulus rupture of a pole. Taras et al. (2004) argued that the strength of a pole is 
subject to decay over time and a pole may fail due to lateral bending. United States utility companies have struggled to strike a balance between over- and under-preparation because they lack a rigorous methodology with which to estimate the damage caused by hurricane winds (Guikema et al. 2010). Various methods have been proposed by researchers to increase the reliability of power distribution systems under wind-related disasters and to decrease the time required to restore damaged systems. These efforts can be largely divided into two groups: predictive models and storm hardening models (Salman et al. 2015; Wanik et al. 2015). Predictive models are popular because they can support pre-event activities for better resource allocations. Some of the notable previous works that proposed predictive models are:

- Guikema et al. (2010) developed a model to predict the number of utility poles that need to be replaced based on wind-related damage data from previous storms by applying regression analysis and data-mining techniques;

- Salman et al. (2015) applied fragility analysis and Monte Carlo simulation to determine the probability of pole failure with varying wind speeds from which they proposed targeted hardening strategies based on an index of important components. They considered the whole system rather than an individual pole;

- Ouyang and Duenas-Osorio (2014) introduced a component fragility model to quantify the resilience of the electric power system in which poles are considered to estimate the fragility of the entire distribution system;

- Shafieezadeh et al. (2013) developed a fragility curve of wooden poles based on the moment capacity of the pole and the moment demand placed on those poles by wind loads. However, they did not consider the deflection and deformation of a pole incurred by wind loads;

- Darestani et al. (2016) proposed a boundary model to capture the boundary effects of adjacent wooden poles in response to wind-induced forces. They used a timedependent decay model and a probabilistic wind model to perform a Monte Carlo simulation to determine the probability of pole failure.

In contrast to Darestani and his colleagues, the present study is focused on the evaluation of the condition of individual poles. In our study, the angular deflection of a pole due to wind force is considered as damage to the pole, and a damage prediction model is proposed to predict pole failure based on its angular deflection.

\subsection{Cost-Benefit Analysis}

Several studies have been conducted to perform a costbenefit analysis on upgrading the electric power distribution network. In the Caribbean Disaster Mitigation Project (1996), a cost-benefit analysis was conducted on the replacement of wooden poles to mitigate damage due to hurricanes. The results of the analysis revealed that the replacement of the wooden poles in a high voltage network with Class 1 poles results in a significant cost saving, but the same action with the lower voltage network is over investment. Taras et al. (2004) considered the cost of poles, labor expenses, and power outage cost as the cost of pole replacement. Quanta Technology (2009) conducted a costbenefit analysis of utility infrastructure upgrades and storm hardening programs based on data collected from several utility companies. In Quanta report, the estimated benefits were calculated against the duration of a power outage and the projected rate of failure or damage. Results were evaluated by selecting and strengthen $10 \%$ of distribution poles in Texas, the United States. The potential net benefit from the hardening was estimated as well. However, it did not show how the most vulnerable part of the distribution network was selected for strengthen purpose. Chang (2003) developed a framework of extended life-cycle cost to evaluate efforts for mitigating the impact of disaster on infrastructure systems. This framework consists of four major costs-planned cost, associated cost imposed on the society, unplanned cost, and societal cost due to a power outage. Salman et al. (2015) adopted Chang's framework to evaluate the cost-effectiveness of a targeted hardening strategy for a power distribution system that is susceptible to the impact of hurricane damage under both probabilistic and scenario-based hurricane conditions.

\section{Poles of the Electrical Power Distribution Network}

The poles of an electric power distribution network in wind-prone regions suffer from various types of damage. Evaluation of the condition of poles is thus imperative. The ability to predict potential damage to poles before the occurrence of a wind-related disaster enables decision makers to plan preventive maintenance operations in a timely manner and to allocate resources effectively. To this end, it is necessary to understand the physical properties of a pole. The following briefly summarizes the material properties and geometry of the utility poles of an electrical power distribution network.

Poles are made of various materials, such as wood, steel, concrete, fiber reinforced polymers, laminated wood, and so on. Wood is the most commonly used in the United 
States for the poles of a distribution system because of its cost-effectiveness and functionality (Daugherty 1998; Crosby 2011). In particular, the southern yellow pine is the most widely used in North America (Dunn and Young 2004); for this reason, it was selected for examination in this study. Modeling a wooden pole is complex due to the natural imperfections of wood, which may affect the expected behavior of the material. It is difficult to determine the mechanical properties of a wooden pole because of its greatly variant elastic behavior (Dias et al. 2007). The mechanical properties of southern yellow pine are different for each orthotropic direction and variant under tension and compression. Under compression, it shows plastic behavior, which can be described by connecting the elasticplastic law. On the other hand, it is likely to show brittle behavior under tension (Federal Highway Administration 2007).

The geometry of a pole is an important parameter for designing and determining the angular deflection of that pole from its original position due to wind-induced forces. Utility companies in the United States commonly use two methods to design their poles - the National Electric Safety Code (NESC 2002) and the standards of American Society of Civil Engineers (ASCE 2006a). Meanwhile, the specifications and dimensions of poles are established by the standard number, ANSI O5.1, of the American National Standards Institute (ANSI 2017). ASCE (2006b) provides minimum design loads for buildings and other structuresa standard that was used as a reference for wind load provision in this study. The pole height was assumed to be $12.19 \mathrm{~m}$ with a taper ratio of $0.263 / 0.154\left(\mathrm{Dia}_{\mathrm{gnd}} / \mathrm{Dia}_{\text {top }}\right.$, $\mathrm{m} / \mathrm{m}$ ). The top of a pole is normally connected with two or more electric cables, which exert tensional forces. However, for simplicity, the cables connecting poles were not taken into consideration because the present study aims to explain the direct impact of wind force on poles. For a comprehensive picture, it will eventually be necessary to examine the effect of tensile forces exerted on poles by the connecting cables. In the present study, the top of a pole was assumed to be free of support whereas the bottom of a pole was considered to have fixed support. Wind force was considered to be uniformly distributed on the pole while the gravitational force on the pole is perpendicular to the surface of the ground.

\section{The Proposed Framework}

This study proposes a framework to predict damage to poles based on the pole angular deflection and measurement of the resilience of poles (Fig. 1). The following subsections delineate the framework.

\subsection{Force Analysis Model for Damage Prediction}

The photogrammetry-based technique is utilized to measure the current angle of a pole. Given the determined angle and the properties of a pole, two types of force that are exerted-gravitational force and wind force-are calculated. The total force, which is the summation of gravitational and wind forces, is defined as a resilience metric in this study. Figure 2 illustrates the two forces (Eren Tokgoz et al. 2017).

The gravitational force is perpendicular to the ground. Thus, the component of gravitational force acting perpendicular to the pole can be expressed as

$F_{g \perp}=F_{g} \sin \theta=m g \sin \theta$

where $F_{g}=$ gravitation force acting on the center of a pole. The wind force is parallel to the ground and uniformly distributed on the pole and can be expressed as

$F_{w}=C P A$

where $F_{w}=$ uniformly distributed wind force, $P=$ wind pressure, $A=$ cross-sectional area, and $C=\mathrm{a}$ constant converting the wind force from pound-force (lbf) to Newton (N). $C$ is needed since the wind force and the height of a pole were considered as miles per hour and feet, respectively, at the beginning of the calculations. According to the Standard Specifications for Structural Supports for Highway Signs, Luminaires, and Traffic Signals (AASHTO 2013), the wind pressure on the pole can be calculated as

$P=0.00256 K_{z} G_{h} C_{d} V^{2}$

where $V$ is the 3 -second peak gust wind speed in the region where the pole is located, $K_{z}$ is the exposure coefficient, $G_{h}$ is the gust response factor, and $C_{d}$ is the drag coefficient. Meanwhile, the uniformly distributed force, $F_{w}$, can be converted into a concentrated load at the center of a pole.

Thus, the component of wind force acting perpendicular to the pole can be expressed as

$F_{w \perp}=F_{w} \cos \theta$

Therefore, the total force due to the gravitational and wind forces can be expressed as

$$
\begin{aligned}
F(\theta, h, r, V) & =F_{g \perp}+F_{w \perp} \\
& =m g \sin \theta+0.00512 C K_{z} G_{h} C_{d} V^{2} h r \cos \theta
\end{aligned}
$$

The mathematical model, Eq. 5, can be used to predict the force acting on a pole under various conditions of wind speeds and material properties of a pole.

A three-dimensional finite element analysis is performed to analyze the mechanical properties and capacity of a 
Fig. 1 An illustration of the proposed framework to determine the resilience of poles

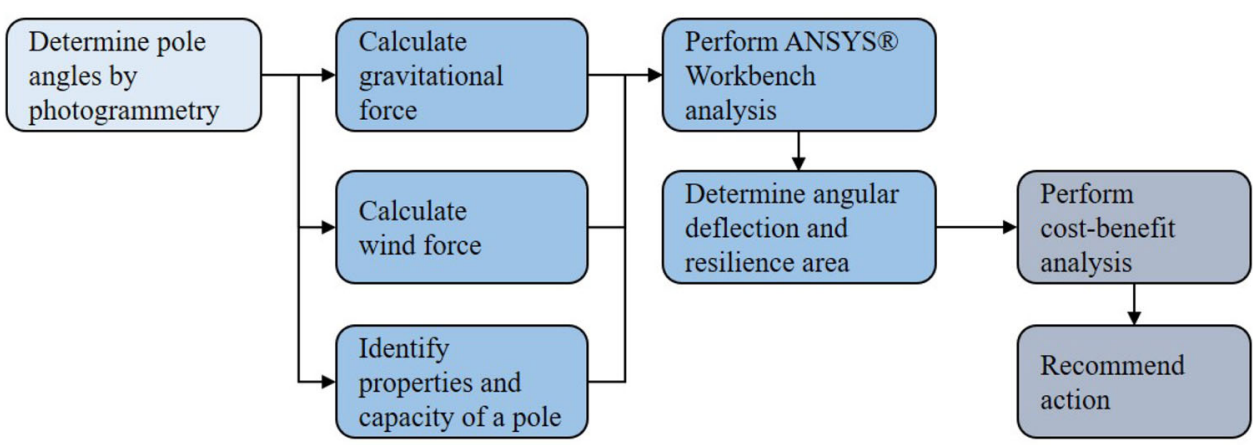

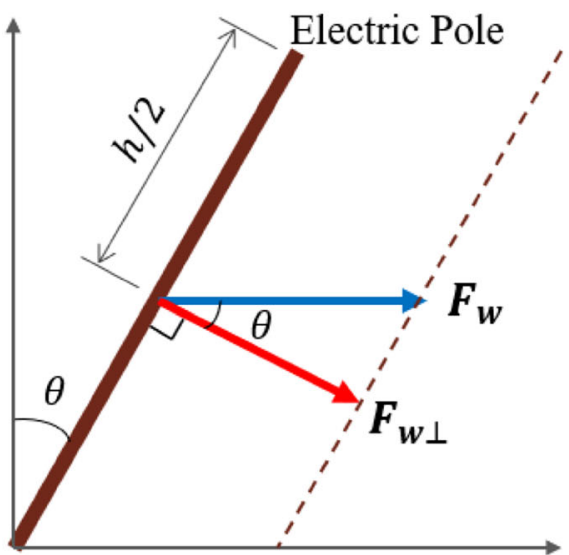

(a)

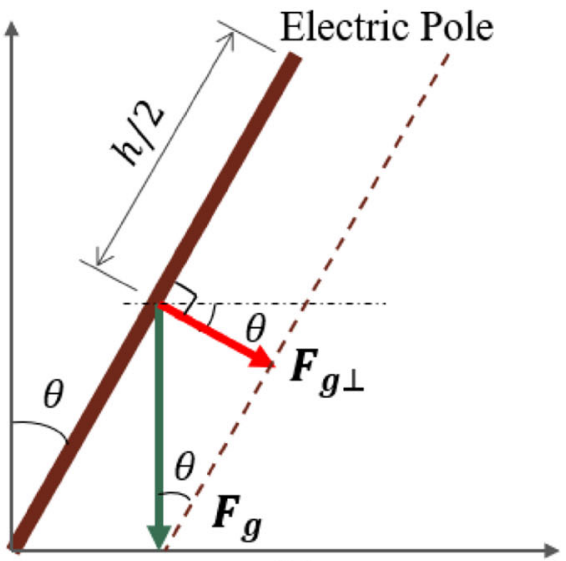

(b)
Fig. 2 Elements that determine pole capacity: a the wind load on a pole and $\mathbf{b}$ the gravitational load on a pole wooden pole. ANSYS ${ }^{\circledR}$ Workbench $^{1}$ is used as a platform for the finite element analysis. Input data for the analysis include the varying wind speeds and pole angles as well as the properties of the material. Table 1 presents the material properties of a southern yellow pine pole. The output of the analysis is the amount of angular deflection of a pole for each combination of a certain force.

In this analysis, the resilience conditions of a pole are defined based on the angular deflection of a pole-the angle $(\theta)$ range $0 \leq \theta<15,15 \leq \theta<25$, and $25 \leq \theta$ corresponds to healthy (resilient), critical (moderately resilient), and unhealthy (non-resilient), respectively (Alam et al. 2018). The angle range for each resilient condition is an expert judgment-driven parameter and the range values were determined by an expert with more than 25 years of experience in the management of a power distribution system at a major utility company. The range values and corresponding resilient conditions were reviewed and accepted by additional two experts working at the same company. It is worth noting that there are no standard values of the angle range. Thus, the parameter values can vary depending on the choice of a utility company. Eren Tokgoz et al. (2017) proposed a set of recommended

${ }^{1}$ ANSYS $^{\circledR}$ Workbench is a finite element analysis software package used to simulate engineering problems.
Table 1 Material properties of a southern yellow pine pole

\begin{tabular}{lll}
\hline Properties & Value & Unit \\
\hline $\begin{array}{l}\text { Density } \\
\text { Isotropic elasticity }\end{array}$ & 553.6 & $\mathrm{~kg} / \mathrm{m}^{3}$ \\
$\quad$ Derived from & Young's modulus & \\
Young's modulus & 89,632 & $\mathrm{MPa}$ \\
Poisson's ratio & 0.3 & \\
Bulk modulus & $7.4693 \mathrm{E}+10$ & $\mathrm{~Pa}$ \\
Shear modulus & $3.4474 \mathrm{E}+10$ & $\mathrm{~Pa}$ \\
Tensile ultimate strength & 55.158 & $\mathrm{MPa}$ \\
Compressive ultimate strength & 31.026 & $\mathrm{MPa}$ \\
\hline
\end{tabular}

actions per the resilience conditions as follows. If a pole is in a healthy condition, then an immediate mitigation action is not needed. If a pole is in a critical condition, then an examination should follow to determine whether a corrective action must take place immediately or not. Lastly, if a pole is in an unhealthy condition, then an immediate corrective action, that is, maintenance or complete replacement of the pole, is needed. 


\subsection{Resilience Model}

There are a few previous studies that produced a resilience model or framework. Willis (2014) argued that resilience could be evaluated for different systems, disruptions, responses, and time-scales based on inputs, capacities, capabilities, and performance or outcomes. Phillips and Tompkins (2014) defined the resilience of critical infrastructure as preparedness, mitigation, response, and recovery. The Sandia National Laboratories (2014) have maintained that a resilience metric is an effective tool for quantifying uncertainty, making decisions for planning and operation, and examining the validity of the decisions.

In our study, a resilience model was developed taking into consideration the angular deflection of a pole (Fig. 3). The model consists of four sequential components of resilience - anticipate, absorb, response, and recovery. This model can address multiple aspects through a proactive approach rather than a reactive one. As part of the proactive approach, the potential wind-related disaster is anticipated. Based on the existing pole angle and calculated wind load, the most vulnerable part of the distribution systems can be detected. Once the threats and vulnerable parts are identified, the capacity of the systems needs to be measured. This capacity can be called an absorptive capacity of the system, which is the ability of the system to withstand damage during a disruptive event without any significant deviation from its normal condition. To the greatest possible extent, the uncertainties about pole damage due to wind force need to be quantified. In this case, the angular deflection of the pole from its original position is considered as damage to the pole. Based on the angular deflection, the pole's resilience condition can be evaluated. The response to any wind-related disaster can be compared at two situations: (1) with corrective action; and (2) without corrective action before the disaster. The last step of this model is recovery, which refers to how quickly and cost effectively the system can return to its normal operative condition. The availability of the resources and their better distribution can ensure a quick recovery with low cost. Using the model, decision makers can produce an effective plan for preparation, mitigation, and recovery. It also allows decision makers to effectively prioritize required actions and allocate limited resource according to the prioritization results.

\subsection{Cost-Benefit Analysis Approach}

The total cost of damage due to wind-related events can be found by summing the cost of a pole replacement, revenue loss of the utility company, and economic loss of the customers (Taras et al. 2004). The replacement cost is a fixed cost for removing the existing pole and installing a new pole. The fixed cost is usually higher when the replacement of a damaged pole is done after an event has occurred (Quanta Technology 2009). The revenue loss of utility companies and loss of societal economy due to the interrupted power supply are the power interruption costs (Chang 2003; Quanta Technology 2009). The cost of revenue loss to the utility company is the volume of unmet demand due to the system's delivery failure and the unit price of electric power (Chang 2003). The volume can be determined by the number of the customers without power, their average consumption rate, and the time needed to restore power. Chang (2003) demonstrated this cost for an earthquake disaster, which was adopted here for a windrelated disaster. The expected cost of revenue loss can be expressed as

$C_{v}=T_{r} \times N_{\text {out }} \times P_{\text {avg }} \times r$

where $C_{v}=$ the cost of revenue loss of the utility company, $T_{r}=$ the time to restore power after a disaster, $N_{\text {out }}=$ the number customers without power, $P_{\text {avg }}=$ the average power consumption per customer, and $r=$ the unit price of electric power. The output of the economic activities can be measured by gross domestic product (GDP) of the region or country. Thus, the cost of economic loss can be measured by the loss of economic activities due to the interrupted power supply and economic shutdown time (Quanta Technology 2009). The expected cost of economic loss can be expressed as

$C_{e}=T_{e} \times N_{\text {out }} \times E$

where $C_{e}=$ the cost of economic loss to the customer, $T_{e}=$ the economic shutdown time, and $E=$ the economic loss due to power interruption based on GDP. The expected benefit is calculated against the amount of expected damage and the duration of a power outage. Pre-event actions for upgrading the poles would reduce the severity of damages, and thus the avoided cost can be considered as a benefit. Therefore, investment for the corrective action is considered as pre-event action cost.

\section{A Case Study}

A case study was conducted to evaluate the methodology that is explained in Sect. 4. The base framework is implemented on some random poles in a particular area that is very prone to hurricanes. Replicates of the randomly generated 1000 poles were generated based on sample poles to implement the methodology. The results of the predicted angular deflections for different wind speed are given in this section. Further, cost-benefit analysis results that consist of three corrective actions are given in this section. 
Fig. 3 A proposed resilience model

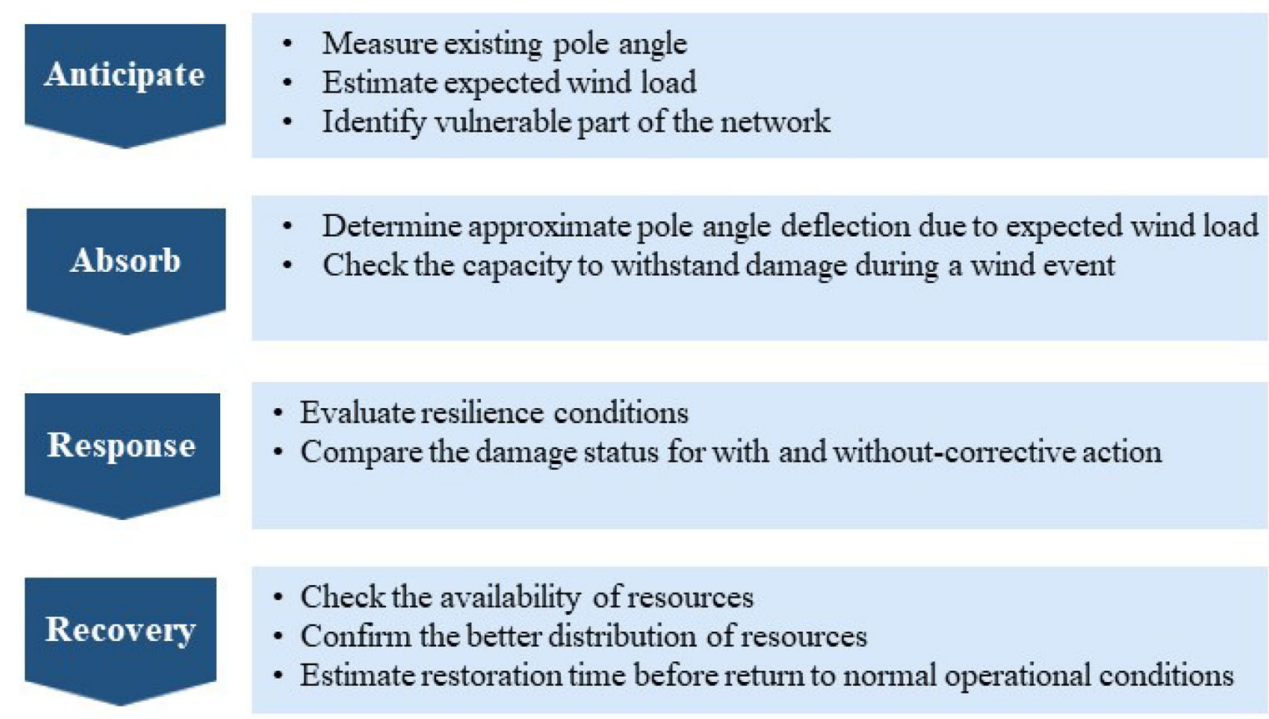

\subsection{Angular Deflection of the Electric Pole}

Twenty-two electric poles were selected as samples for a case study. The poles are located along the two major transit roads-S. Martin Luther King Jr Parkway and Highway 69-in the city of Beaumont, Texas. This area is very prone to hurricanes. The area experienced a devastating flood caused by the largest amount of rainfall recorded in the United States during Hurricane Harvey in 2017. Other most recent hurricanes that affected the same area were Hurricane Rita and Hurricane Ike in 2005 and 2008 , respectively. Thus, the selected area for a case study well represents areas for which the developed methodology

Table 2 Sample data of existing pole conditions in Beaumont, Texas before exposure to further wind stress. Source Adapted from Eren Tokgoz et al. (2017)

\begin{tabular}{|c|c|c|c|}
\hline \multicolumn{2}{|c|}{ S. Martin Luther King Jr. Pkwy } & \multicolumn{2}{|c|}{ Highway 69} \\
\hline Pole \# & Angle $(\theta)^{\circ}$ & Pole \# & Angle $(\theta)^{\circ}$ \\
\hline 1 & 17 & 12 & 2 \\
\hline 2 & 21 & 13 & 4 \\
\hline 3 & 13 & 14 & 5 \\
\hline 4 & 26 & 15 & 3 \\
\hline 5 & 11 & 16 & 17 \\
\hline 6 & 17 & 17 & 12 \\
\hline 7 & 4 & 18 & 9 \\
\hline 8 & 17 & 19 & 18 \\
\hline 9 & 12 & 20 & 12 \\
\hline 10 & 14 & 21 & 15 \\
\hline 11 & 7 & 22 & 8 \\
\hline
\end{tabular}

is intended to be implemented. The angular deflection $(\theta)$ of poles was found by using photogrammetry technology (Table 2). Given the small size of the original sample (pole angles of 22 poles) and the large sample variance, the sample was propagated from 22 to 1000 using the negative binomial distribution to perform a finite element analysis. A finite element analysis was performed using ANSYS $^{\circledR}$ Workbench to evaluate the resilience condition of the 1000 poles based on their angular deflection. Wind speeds of 90 , $100,120,140$, and $160 \mathrm{mph}$ were selected and applied to each pole within each hurricane category, which is determined by the Saffir-Simpson hurricane category scale. The amount of angular deflection of each pole was then calculated for each wind speed and represented as $\theta_{1}, \theta_{2}, \theta_{3}$, $\theta_{4}$, and $\theta_{5}$. These calculated angular deflections were added to the selected angles of $5^{\circ}, 10^{\circ}, 15^{\circ}, 20^{\circ}$, and $25^{\circ}$. Table 3 presents the partial results. Figure 4 presents an example of the results of the finite element analysis. Various pole failure testing methods are available. Among them "setting poles in the earth and applying load at the middle of the pole height" was selected and applied using $\operatorname{ANSYS}^{\circledR}$ Workbench. Figure 4 shows that the maximum deflection occurs at the top of a pole and the minimum deflection at its bottom.

Figure 5 presents the percentages of the resilient (green), moderately resilient (yellow), and non-resilient (red) conditions of the poles. The results show that the initial wind thrust caused a significant problem to the poles. The number of poles moved from moderately resilient region to non-resilient region was comparatively more than the number of poles moved from resilient to moderately resilient region. There is no significant change to those numbers as the wind speed increases due to a few reasons. 
Table 3 Angular deflections in wooden utility poles for different wind speeds (degree)

\begin{tabular}{lccccc}
\hline$\theta$ & $\theta_{1}$ at $90 \mathrm{mph}$ & $\theta_{2}$ at $100 \mathrm{mph}$ & $\theta_{3}$ at $120 \mathrm{mph}$ & $\theta_{4}$ at $140 \mathrm{mph}$ & $\theta_{5}$ at $160 \mathrm{mph}$ \\
\hline 5 & 5.50 & 5.55 & 5.64 & 5.75 & 11.04 \\
10 & 10.80 & 10.85 & 10.93 & 16.31 & 11.17 \\
15 & 16.06 & 16.10 & 16.19 & 21.55 & 16.43 \\
20 & 21.28 & 21.31 & 21.40 & 26.62 & 21.67 \\
25 & 26.43 & 26.46 & 26.53 & 26.72 \\
\hline
\end{tabular}

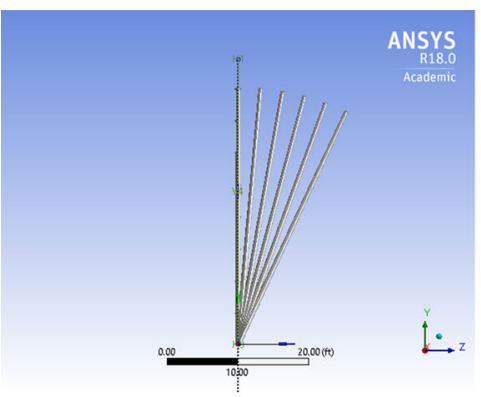

(a)

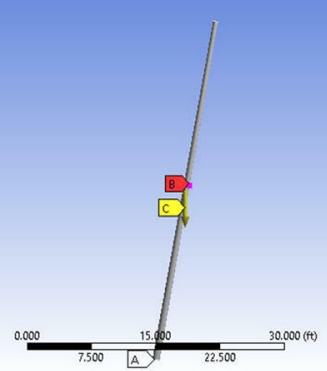

(b)
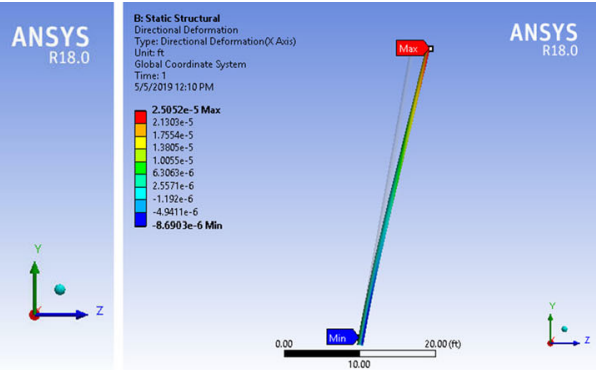

(c)

Fig. 4 Angular deflection of utility poles under stress: a the positions of a pole at $0^{\circ}, 5^{\circ}, 10^{\circ}, 15^{\circ}, 20^{\circ}$, and $25^{\circ}$; $\mathbf{b}$ the boundary conditions used in ANSYS ${ }^{\circledR}$ Workbench; and $\mathbf{c}$ the directional deflection of a pole

Fig. 5 Changes in the resilience status of utility poles because of a wind event

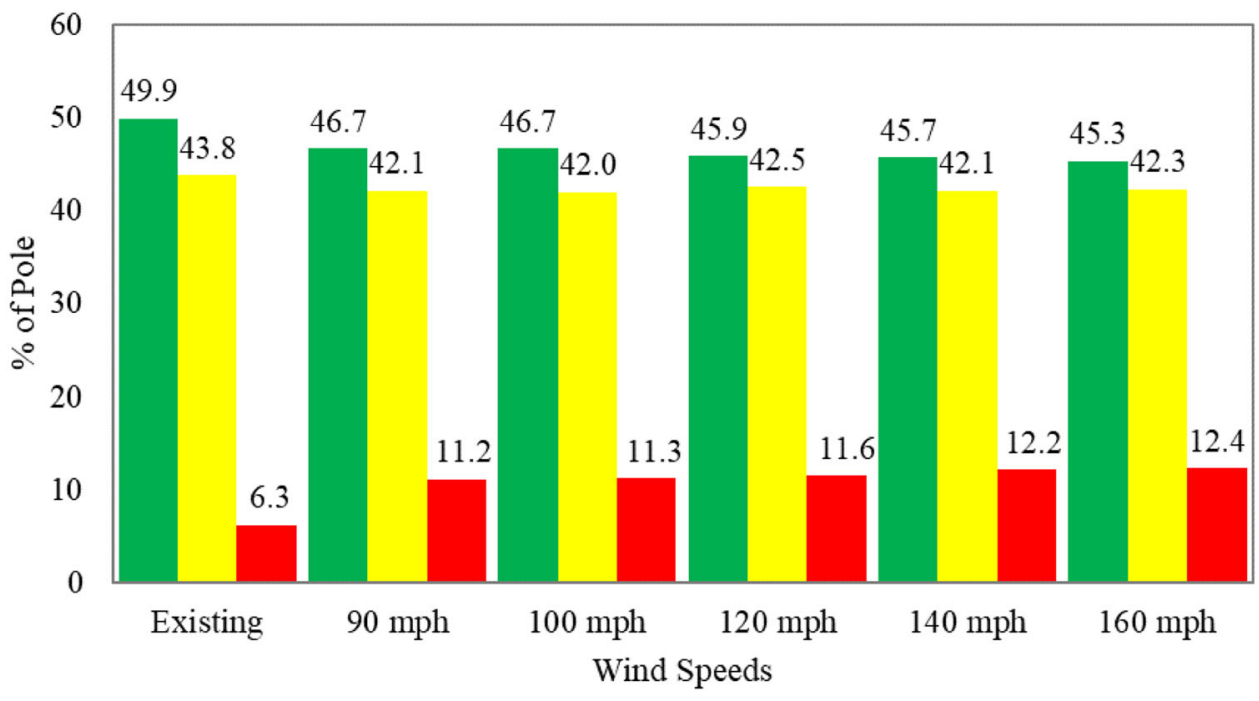

Resilient Moderately Resilient $\square$ Non-Resilient

For instance, the data points might be very close to a maximum value of the resilient angle range $(0 \leq \theta<15)$. So, once they moved from the maximum value of resilient angle to the minimum value of moderately resilient angle range $(15 \leq \theta<25)$, they need more forces to move to the non-resilient region. Table 4 shows the percentages of poles of that shifted in resilience condition from resilient to moderately resilient and from moderately resilient to nonresilient.

\subsection{Results of Cost-Benefit Analysis}

Cost-benefit analysis was conducted to show the merits of a resilience metric. It compares losses and savings for different pole conditions and corrective actions. Three strategies have been considered:

Strategy 1: No corrective action

Strategy 2: Corrective action that replaces only existing unhealthy poles 
Table 4 Percentage of resilience condition changes in utility poles relative to wind speed

\begin{tabular}{lll}
\hline Wind speeds $(\mathrm{mph})$ & Resilient to moderately resilient $(\%)$ & Moderately resilient to non-resilient $(\%)$ \\
\hline 90 & 3.2 & 4.9 \\
100 & 3.2 & 5.0 \\
120 & 4.0 & 5.3 \\
140 & 4.2 & 5.9 \\
160 & 4.6 & 6.1 \\
\hline
\end{tabular}

Strategy 3: Corrective action that replaces both existing and predicted unhealthy poles.

The total cost of damage was calculated based on a cost-benefit analysis approach. The replacement cost per pole was determined to be USD 2500 before a disaster event and USD 4000 after a disaster event based on Quanta Technology (2009) and the experts' assessment. Three types of customer groups were considered-residential, commercial, and industrial customers. Each customer group has an average power consumption rate and an average economic loss due to a disaster event, which is different for each group. The size of the customer groups was assumed in this analysis to be $80 \%$ residential, $10 \%$ commercial, and $10 \%$ industrial. This cost-benefit analysis was conducted for a wind speed of $120 \mathrm{mph}$, which represents a Category 3 hurricane. The resulting damages were limited to wind-related damage to poles only.

Table 5 summarizes the data set used for the costbenefit calculations. Tables 6,7 , and 8 present the results of the cost-benefit analysis for three corrective action strategies, respectively. Table 6 shows that $11.60 \%$ of poles is in non-resilient condition, which was originally $6.3 \%$. Approximately $5.3 \%$ of poles was predicted to fall in non-resilient condition under a Category 3 wind speed. Thus, the total percentage of non-resilient poles is $11.60 \%$ $(5.3+6.3)$. When Strategy 1 is implemented, all unhealthy poles were assumed to fail, and the total incurred cost is about USD 8.5 million. If decision makers decide to invest money into the corrective action only for existing nonresilient poles, which is Strategy 2 in this study, then the avoided cost may be considered as a benefit. In Strategy 2, USD 0.16 million investment is required to replace the existing non-resilient poles, which can reduce the initial loss down to around USD 3.6 million instead of USD 8.5 million. This saving is calculated to be approximately USD 4.9 million (USD 8.5-USD 3.6) as shown in Table 7. If decision makers choose to invest money into the corrective action to replace both existing and predicted non-resilient poles, which is Strategy 3 in this study, then, there is theoretically no loss. The predicted non-resilient poles are the ones moving from moderately resilient condition to non- resilient condition under Category 3 wind speed. Table 8 shows the results of Strategy 3 implementation, requiring approximately USD 0.3 million investment to avoid loss to the distribution network due to the pole inclination angle. It should be noted that these results do not account for other causes of pole damages such as falling trees or branches on a pole and foundation failures.

Figure 6 illustrates the results of the cost-benefit analysis of the three predetermined corrective action strategies presented in Tables 6, 7, and 8. Since the strategies are set with the number of vulnerable poles, the cost-benefit analysis can be effectively used to evaluate different resilience actions for future events. For example, using the analysis method, decision makers can set how much resilience they want to gain or how much money they want to invest to strengthen their distribution system against no corrective action option.

Figure 6 graphically presents the result of cost-benefit analysis in which a Category 3 hurricane wind speed was considered. The results show that if a decision maker follow Strategy 1, the damage cost will be approximately USD 8.5 million. Strategy 2 shows that an investment of around USD 0.16 million can reduce the damage cost from USD 8.5 million to USD 3.6 million, which can save USD 4.9 million. Strategy 3 shows that an investment of about USD 0.3 million is needed to take care all non-resilient poles, which can save USD 8.5 million damage cost.

\section{Conclusion}

Utility poles are one of the critical components of the electrical power distribution network, because the poles are frequently damaged by the wind-related disasters. We believe that evaluation of pole condition and estimation of potential damage before and after the occurrence of disasters will help decision makers increase their capacity to prepare for and recovery from wind-related disasters. A framework for predicting pole damages is proposed in this study; the ultimate purpose of the framework is to determine the resilience area of a pole for pre- and post-disaster situations. The methodology also can enable utility 
Table 5 The cost-benefit analysis data sources

\begin{tabular}{lll}
\hline Data descriptions & Value & Source \\
\hline Total pole & 1000 & Assumed \\
Pole location & Coastal region & Study area \\
Pole per mile & 30.5 & Quanta Technology (2009) \\
Customer per mile & 31 & Quanta Technology (2009) \\
Residential customer & $80 \%$ & Assumed \\
Commercial customer & $10 \%$ & Assumed \\
Industrial customer & $10 \%$ & Assumed \\
Average consumption by residential & $1.5 \mathrm{KW} / \mathrm{h}$ & EIA (2018) \\
Average consumption by commercial & $10.1 \mathrm{KW} / \mathrm{h}$ & EIA (2018) \\
Average consumption by industrial & $39.4 \mathrm{KW} / \mathrm{h}$ & EIA (2018) \\
Average price of electricity (USD) & $0.11 / \mathrm{KW} / \mathrm{h}$ & EIA (2018) \\
Economic loss to residential (USD) & $2.70 / \mathrm{h}$ & LaCommare and Eto (2006) \\
Economic loss to commercial (USD) & $886 / \mathrm{h}$ & LaCommare and Eto (2006) \\
Economic loss to industrial (USD) & $3253 / \mathrm{h}$ & LaCommare and Eto (2006) \\
Pole replacement cost during hurricane (USD) & $4000 / \mathrm{pole}$ & Quanta Technology (2009) \\
Days of full restoration for category-3 hurricane & 20 & Quanta Technology (2009) \\
Days of economic loss for category-3 hurricane & 6.7 & Quanta Technology (2009) \\
\hline
\end{tabular}

Table 6 Results for Strategy 1

\begin{tabular}{ll}
\hline Factors & Values \\
\hline$\%$ of poles in a resilient condition & 45.90 \\
$\%$ of poles in a moderately resilient condition & 42.50 \\
$\%$ of poles in a non-resilient condition & 11.60 \\
Investment for corrective action (USD) & 0 \\
Cost of pole replacement (USD) & 464,000 \\
Cost of revenue loss (USD) & 38,808 \\
Cost of economic loss (USD) & $8,027,425$ \\
Total cost (USD) & $8,530,233$ \\
\hline
\end{tabular}

Table 7 Results for Strategy 2

\begin{tabular}{ll}
\hline Factors & Values \\
\hline \% of poles in a resilient condition & $45.90+6.3=52.20$ \\
$\%$ of poles in a moderately resilient condition & 42.50 \\
$\%$ of poles in a non-resilient condition & 5.3 \\
Investment for corrective action (USD) & 162,500 \\
Cost of pole replacement (USD) & 212,000 \\
Cost of revenue loss (USD) & 16,473 \\
Cost of economic loss (USD) & $3,346,424$ \\
Total cost (USD) & $3,574,898$ \\
\hline
\end{tabular}

companies to estimate the amount of time required to fix damaged poles and effectively allocate limited resources to critical preventive maintenance and recovery operations. A
Table 8 Results for Strategy 3

\begin{tabular}{ll}
\hline Factors & Values \\
\hline$\%$ of poles in a resilient condition & $45.90+6.3+5.3=57.50$ \\
$\%$ of poles in a moderately resilient & 42.50 \\
condition & \\
$\%$ of poles in a non-resilient condition & 0 \\
Investment for corrective action (USD) & 295,000 \\
Cost of pole replacement (USD) & 0 \\
Cost of revenue loss (USD) & 0 \\
Cost of economic loss (USD) & 0 \\
Total cost (USD) & 0 \\
\hline
\end{tabular}

generalized cost-benefit analysis approach was implemented in our case study. This approach was used in our evaluation of multiple corrective action strategies. This capability might potentially help utility companies in utilizing their budgets more effectively.

The proposed framework has a few significant limitations when called on to handle a comprehensive list of causes that might damage utility poles. The framework is concerned with the impact of wind loads only, when the poles can deteriorate due to other disasters, such as flooding, earthquake, and snow. Also, it does not take into consideration additional factors that can be associated with the impact of wind load, including soil conditions, trees or branches of trees falling on the cables or poles, over-saturated soil that weakens support of the bottom of a pole, 
Fig. 6 Comparison of the results of the cost-benefit analysis for Category 3 hurricane

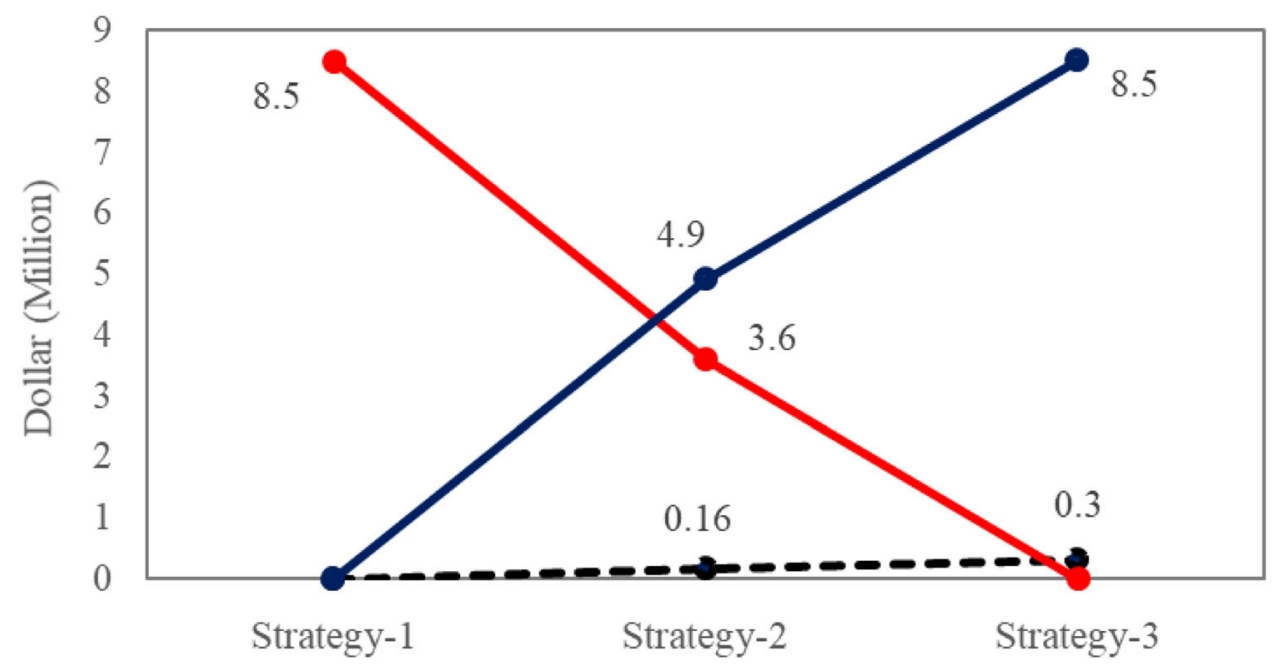

Corrective action strategies

- - Investments $\longrightarrow$ Losses $\longrightarrow$ Savings

and alternative types of pole materials to the widespread preference for wooden poles. The authors plan to explore solutions to these limitations in future research. This research effort will also explore the potential impact of vegetation, such as tree, ivy, and kudzu, growing near the poles and the effect of connecting cables. In addition, the research team plans to explore and test drone-based image collection technology and computer vision technology aiming to expedite field data collection and automated image processing.

Open Access This article is distributed under the terms of the Creative Commons Attribution 4.0 International License (http://crea tivecommons.org/licenses/by/4.0/), which permits unrestricted use, distribution, and reproduction in any medium, provided you give appropriate credit to the original author(s) and the source, provide a link to the Creative Commons license, and indicate if changes were made.

\section{References}

AASHTO (American Association of State Highway and Transportation Officials). 2013. Standard specifications for structural supports for highway signs, luminaires, and traffic signals, 6th edn. Washington, DC: AASHTO.

AEP Texas (American Electric Power Texas). 2017. Hurricane Harvey restoration update-9-3-2017, 4:30 p.m. https://www. aeptexas.com/info/news/viewRelease. aspx ?releaseID=2339. Accessed 15 Feb 2018.

Alam, M.M., B. Eren Tokgoz, M. Safa, and S. Hwang. 2018. Evaluation of effects of wind speed on resilience of electric pole. In Proceedings of the 2018 IISE Annual Conference, 19-21 May 2018, Orlando, Florida, USA, 3 vols., ed. K. Barker, D. Berry, and C. Rainwater (Norcross, GA: Institute of Industrial and Systems Engineers), 216-221. https://www.xcdsystem.com/iise/
2018_proceedings/papers/FinalPaper_1665_0306114917.pdf. Accessed 13 Mar 2019.

ANSI (American National Standards Institute). 2017. Specifications and dimensions (for wood poles, O5.1). New York: ANSI. https://webstore.ansi.org/Standards/ANSI/ANSIO52017?gclid= EAIaIQobChMI74yPio-E4QIVREOGCh1g5Q

X2EAAYAiAAEgKX2fD_BwE. Accessed 12 Apr 2019.

ASCE (American Society of Civil Engineers). 2006a. Reliabilitybased design of utility pole structures. Manuals and reports on engineering practice No. 111, ed. H. Dagher. Reston, VA: ASCE. https://ascelibrary.org/doi/book/10.1061/ 9780784408452. Accessed 12 Apr 2019.

ASCE (American Society of Civil Engineers). 2006b. Minimum design loads for buildings and other structures. SEI/ASCE 7-05, 2nd edn. Reston, VA: ASCE. https://martinyunianto.files.word press.com/2017/04/asce_7-05_minimum_design_loads_for_ buildings_and_other_structures2.pdf. Accessed 14 Mar 2019.

Caribbean Disaster Mitigation Project. 1996. Hurricane vulnerability and risk analysis of the VINLEC transmission and distribution system. Unit for Sustainable Development and Environment, Organization of American States. https://www.oas.org/cdmp/ document/vinlec/vinlec.htm. Accessed 20 Mar 2018.

Carlson, J.L., R.A. Haffenden, G.W. Bassett, W.A. Buehring, M.J. Collins III, S.M. Folga, F.D. Petit, J.A. Phillips, et al. 2012. Resilience: Theory and application. Lemont, IL: Argonne National Laboratory. https://publications.anl.gov/anlpubs/2012/ 02/72218.pdf. Accessed 25 Jan 2018.

Chang, S.E. 2003. Evaluating disaster mitigations: Methodology for urban infrastructure systems. Natural Hazards Review 4(4): 186-196.

Crosby, A. 2011. Special research topic report on current practice in utility distribution poles and light poles. http://www.kornegayen gineering.com/wp-content/uploads/2011/05/structural-utility-dis tribution-light-poles-whitepaper-acrosby.pdf. Accessed 15 Dec 2017.

Darestani, Y.M., A. Shafieezadeh, and R. DesRoches. 2016. An equivalent boundary model for effects of adjacent spans on wind reliability of wood utility poles in overhead distribution lines. Engineering Structures 128: 441-452. 
Daugherty, G.L. 1998. The realistic expectation of an in-place wood pole inspection program: Utility poles and structures. Revised version of a paper presented at the International Conference on Utility Line Structures, 23-25 March 1998, Fort Collins, Colorado, USA. http://rls-cmc.com/in-place-wood-pole-inspec tion-program/. Accessed 12 Apr 2019.

Dias, A.M.P.G., J.W. Van de Kuilen, S. Lopes, and H. Cruz. 2007. A non-linear 3D FEM model to simulate timber-concrete joints. Advances in Engineering Software 38(8-9): 522-530.

Dunn, S.C., and R.R. Young. 2004. Supplier assistance within supplier development initiatives. Journal of Supply Chain Management 40(2): 19-29.

EIA (Energy Information Administration). 2018. Retail sales of electricity to ultimate customers. https://www.eia.gov/electricity/ data.php\#sales.Accessed 11 Jun 2018.

Eren Tokgoz, B., and A.V. Gheorghe. 2013. Resilience quantification and its application to a residential building subject to hurricane winds. International Journal of Disaster Risk Science 4(3): 105-114.

Eren Tokgoz, B., M. Safa, and S. Hwang. 2017. Resilience assessment for power distribution systems. International Journal of Civil and Environmental Engineering 11(7): 806-811.

Executive Office of the President. 2013. Economic benefits of increasing electric grid resilience to weather outages. Washington, DC: Executive Office of the President. https://www.energy. gov/sites/prod/files/2013/08/f2/Grid\%20Resiliency\%20Report_ FINAL.pdf. Accessed 18 May 2018.

Federal Highway Administration. 2007. Measured variability of southern yellow pine-Manual for LS-DYNA wood material model 143. Washington, DC: Federal Highway Administration. https://www.fhwa.dot.gov/publications/research/safety/04097/ sec1x0.cfm. Accessed 12 Apr 2019.

Guikema, S.D., S.M. Quiring, and S.R. Han. 2010. Prestorm estimation of hurricane damage to electric power distribution systems. Risk Analysis: An International Journal 30(12): 1744-1752.

Han, S.R. 2008. Estimating hurricane outage and damage risk in power distribution systems. Ph.D. thesis. College Station, TX: Texas A\&M University. https://oaktrust.library.tamu.edu/bit stream/handle/1969.1/ETD-TAMU-2923/HAN-DISSERTA TION.pdf?sequence=1\&isAllowed=y. Accessed 13 Mar 2018.

Haimes Y.Y. 2009. On the definition of resilience in systems. Risk Analysis: An International Journal 29(4): 498-501.

Hosseini, S., K. Barker, and J.E. Ramirez-Marquez. 2016. A review of definitions and measures of systems resilience. Reliability Engineering and System Safety 145: 47-61.

Kenward, A., and U. Raja. 2014. Blackout: Extreme weather, climate change and power outages. Princeton, NJ: Climate Central. http://assets.climatecentral.org/pdfs/PowerOutages.pdf. Accessed 10 May 2018.

LaCommare, K.H., and J.H. Eto. 2006. Cost of power interruptions to electricity consumers in the United States (US). Energy 31(12): $1845-1855$.

MacKenzie, C.A., and C.W. Zobel. 2016. Allocating resources to enhance resilience, with application to superstorm Sandy and an electric utility. Risk Analysis 36(4): 847-862.

Mukhopadhyay, S., and M. Hastak. 2016. Public utility commissions to foster resilience investment in power grid infrastructure. Procedia-Social and Behavioral Sciences 218: 5-12.

Mukherjee, S., R. Nateghi, and M. Hastak. 2018. A multi-hazard approach to assess severe weather-induced major power outage risks in the US. Reliability Engineering \& System Safety 175: 283-305.

Nan, C., and G. Sansavini. 2017. A quantitative method for assessing resilience of interdependent infrastructures. Reliability Engineering and System Safety 157: 35-53.
NESC (National Electrical Safety Code). 2002. IEEE Standard. Piscataway, NJ: Institute of Electrical and Electronic Engineers.

NOAA (National Oceanic and Atmospheric Administration). 2017. Billion-dollar weather and climate disasters: Table of events. https://www.ncdc.noaa.gov/billions/events/US/1980-2017. Accessed 5 Jan 2018.

Oudjene, M., and M. Khelifa. 2009. Finite element modelling of wooden structures at large deformations and brittle failure prediction. Materials \& Design 30(10): 4081-4087.

Ouyang, M., and L. Dueñas-Osorio. 2014. Multi-dimensional hurricane resilience assessment of electric power systems. Structural Safety 48: 15-24.

Pellicane, P.J., and N. Franco. 1994. Modeling wood pole failure. Wood Science and Technology 28(4): 261-274.

Phillips, J., and A. Tompkins. 2014. Resilience metrics. Prepared for the Quadrennial Energy Review Technical Workshop on Resilience Metrics for Energy Transmission and Distribution Infrastructure, 28 April 2014. Lemont, IL: Argonne National Laboratory. https://energy.gov/sites/prod/files/2015/01/f19/ Argonne\%20National\%20Lab.Resiliency\%20Metrics\%20work shop.pdfl. Accessed 15 Jan 2018.

Quanta Technology. 2009. Cost-benefit analysis of the deployment of utility infrastructure upgrades and storm hardening programs: Final report. Public Utility Commission of Texas Project No. 36375. Raleigh, NC: Quanta Technology. http://www.puc.texas. gov/industry/electric/reports/infra/utlity_infrastructure_ upgrades_rpt.pdf. Accessed 10 Dec 2017.

Ryan, P.C., M.G. Stewart, N. Spencer, and Y. Li. 2014. Reliability assessment of power pole infrastructure incorporating deterioration and network maintenance. Reliability Engineering \& System Safety 132: 261-273.

Schmidt, J., and M. Kaliske. 2009. Models for numerical failure analysis of wooden structures. Engineering Structures 31(2): 571-579.

Salman, A.M., Y. Li, and M.G. Stewart. 2015. Evaluating system reliability and targeted hardening strategies of power distribution systems subjected to hurricanes. Reliability Engineering \& System Safety 144: 319-333.

Sandia National Laboratories. 2014. Energy infrastructure resilience: Framework and sector-specific metrics. Argonne: Argonne National Laboratories (ANL). https://energy.gov/sites/prod/ files/2015/01/f19/SNLResilienceApril29.pdf. Accessed 15 Jan 2018.

Shafieezadeh, A., P.U. Onyewuchi, M.M. Begovic, and R. DesRoches. 2013. Fragility assessment of wood poles in power distribution networks against extreme wind hazards. In Advances in hurricane engineering: Learning from our past, ed. C.P. Jones, and L.G. Griffis, 851-861. Reston, VA: American Society of Civil Engineers.

Taras, A., G. Ratel, and L. Chouinard. 2004. A life-cycle cost approach to the maintenance of overhead line supports. In Reliability and optimization of structural systems, ed. M.A. Maes, and L. Huyse, 241-250. London: CRC Press.

Wanik, D.W., E.N. Anagnostou, B.M. Hartman, M.E.B. Frediani, and M. Astitha. 2015. Storm outage modeling for an electric distribution network in Northeastern USA. Natural Hazards 79(2): 1359-1384.

Willis, H.H. 2014. Resilience metrics for energy systems. Santa Monica, CA: Rand Corporation. https://energy.gov/sites/prod/ files/2015/01/f19/RAND.Resiliency\%20Metrics\%20workshop. pdf. Accessed 15 Jan 2018. 